\title{
Piperonal ciprofloxacin hydrazone induces growth arrest and apoptosis of human hepatocarcinoma SMMC-7721 cells
}

\author{
Zhen-yu SHI ${ }^{1}$, Yong-qiang $\mathrm{LI}^{1}$, YU-hua KANG ${ }^{2}$, Guo-qiang $\mathrm{HU}^{3}$, Chao-shen HUANG-FU ${ }^{1}$, Jin-bo DENG ${ }^{1}$, Bin LIU ${ }^{1, *}$ \\ ${ }^{1}$ Institute of Neurobiology, College of Nursing, He-nan University, Kaifeng 475004, China; ${ }^{2}$ Huai-he Clinical College, He-nan University \\ Kaifeng 475001, China; ${ }^{3}$ Institute of Chemical Biology, He-nan University, Kaifeng 475004, China
}

Aim: To investigate the cytotoxic effects of piperonal ciprofloxacin hydrazone (QNT4), a novel antibacterial fluoroquinolone derivative, against human hepatocarcinoma SMMC-7721 cells.

Methods: Human hepatocarcinoma cells (SMMC-7721), human breast adenocarcinoma cells (MCF-7) and human colon adenocarcinoma cells (HCT-8) were tested. The effects of QNT4 on cell proliferation were examined using MTT assay. Cell apoptosis was determined using Hoechst 33258 fluorescence staining, TUNEL assay and agarose gel electrophoresis. The topoisomerase II activity was measured using agarose gel electrophoresis with the DNA plasmid pBR322 as the substrate. Mitochondrial membrane potential ( $\Delta \psi \mathrm{m})$ was measured using a high content screening imaging system. Protein expression of caspase-9, caspase-8, caspase-3, p53, Bcl-2, Bax, and cytochrome $c$ was detected with Western blot analysis.

Results: Treatment with QNT4 $(0.625-10 \mu \mathrm{mol} / \mathrm{L})$ potently inhibited the proliferation of the cancer cells in time- and dose-dependent manners (the $\mathrm{IC}_{50}$ value at $24 \mathrm{~h}$ in SMMC-7721 cells, MCF-7 cells and HCT-8 cells was 2.956 $\pm 0.024,3.710 \pm 0.027$, and 3.694 \pm 0.030 $\mu \mathrm{mol} / \mathrm{L}$, respectively). Treatment of SMMC-7721 cells with QNT4 $(0.2146,2.964$, and $4.600 \mu \mathrm{mol} / \mathrm{L})$ for $24 \mathrm{~h}$ dose-dependently increased the percentage of apoptotic cells, elicited characteristic DNA “ladder" bands, and decreased the mitochondrial membrane potential. QNT4 dose-dependently increased topoisomerase II-mediated DNA breaks while inhibiting DNA relegation, thus keeping the DNA in fragments. Treatment of SMMC-7721 cells with QNT4 significantly increased cytochrome c in the cytosol, and decreased cytochrome $\mathrm{c}$ in the mitochondrial compartment. QNT4 (3-7.39 $\mu \mathrm{mol} / \mathrm{L})$ significantly increased the protein expression of p53, Bax, caspase- 9 , caspase-3, and the cleaved activated forms of caspase- 9 and caspase-3 in SMMC-7721 cells. In contrast, the expression of $\mathrm{Bcl}-2$ was decreased, while caspase-8 had no significant change.

Conclusion: QNT4 induced the apoptosis of SMMC-7721 cells via inhibiting topoisomerase II activity and modulating mitochondrialdependent pathways.

Keywords: anticancer drug; fluoroquinolone; piperonal ciprofloxacin hydrazone; hepatocarcinoma cells; breast adenocarcinoma cells; colon adenocarcinoma cells; apoptosis; topoisomerase II; mitochondrial membrane potential

Acta Pharmacologica Sinica (2012) 33: 271-278; doi: 10.1038/aps.2011.158

\section{Introduction}

Antibacterial fluoroquinolone is a very important family of antibacterial drugs that are widely prescribed for the treatment of infections in humans ${ }^{[1]}$. According to the pharmacological mechanisms elucidated in numerous reports, antibacterial fluoroquinolone corrupts the activities of prokaryotic type II topoisomerase and DNA gyrase, and induces them to kill cells by generating high levels of DNA double-strand breaks. DNA gyrase modulates the topological state of the genetic material

\footnotetext{
* To whom correspondence should be addressed.

E-mail lbgood5912@sina.com

Received 2011-04-20 Received 2011-10-28
}

by passing an intact DNA helix through a transient doublestrand break that is generated in a separate DNA segment ${ }^{[2]}$. Like bacterial cells, eukaryotic species also require a type II topoisomerase, known as topoisomerase II, for viability. Compared with the known sequences of type II topoisomerases of bacteria and mammals, the sequences around activated tyrosine residues appear to have common homology $y^{[3]}$. The mechanisms by which antitumor fluoroquinolones induce cell death appear to be similar to those of quinolone antibacterial agents ${ }^{[4]}$. Mammalian DNA topoisomerase II can be inhibited by fluoroquinolones, although it is 100 -fold more sensitive to prokaryotic DNA gyrase. In addition, the mode of action of fluoroquinolones is similar to that of anthracycline derivatives 
(such as doxorubicin, amsacrine, mitoxantrone), epipodophyllotoxin derivatives (such as etoposide), and actinomycin D (a class of polypeptide antibiotics isolated from Streptomyces). Accordingly, antibacterial fluoroquinolones have been shown to be cytotoxic to cancer cells ${ }^{[5,6]}$, thus representing a potentially important source of new anticancer agents. Recently, the development of antitumor agents derived from antibacterial fluoroquinolones has attracted much attention due to the mechanistic similarities and sequence homologies of the targeting eukaryotic topoisomerases ${ }^{[7]}$. However, many antitumor fluoroquinolones have been modified from clinical antibacterial fluoroquinolones with regard to the nitrogencontaining ring, such as piperazine, on the 7-position and (or) the 2-position of the fluoroquinolone scaffold ${ }^{[8,9]}$. In addition, a few modifications of the carboxylic group at the 3-position have been reported ${ }^{[10]}$. Indeed, it does not seem necessary for an antitumor fluoroquinolone to retain the carboxylic group; fluoroquinolones with a fused heterocyclic ring as an isostere of the carboxylic group showed strong anticancer activity as well as high water solubility ${ }^{[11]}$. To search for new structural modification strategies for antibacterial fluoroquinolones, we have designed and synthesized a series of fluoroquinolone derivatives by linking various hydrazine compounds to the C-3 carboxyl group of ciprofloxacin or ofloxacin and assessed their anticancer activities. Several novel ciprofloxacin derivatives displayed potent cytotoxicity against the tested cancer cell lines in vitro, with $\mathrm{IC}_{50}$ values reaching micromolar concentrations $^{[12]}$. In this study, we investigated the growth inhibitory effects and the molecular mechanisms of piperonal ciprofloxacin hydrazone (QNT4) in human hepatocarcinoma SMMC-7721 cells. We found that QNT4 (1-cyclopropyl-6-fluoro-4-oxo-7-piperazin-1, 4-dihydro-quinoline-3-carboxylic acid benzo[1,3]dioxol-5-ylmethylene-hydrazide) showed potent cytotoxicity against SMMC-7721 cells with an $\mathrm{IC}_{50}$ value of $2.411 \mu \mathrm{mol} / \mathrm{L}$.

\section{Materials and methods Chemicals}

Piperonal ciprofloxacin hydrazone (QNT4) was synthesized at the Institute of Chemistry and Biology at Henan University. The purity was $>98 \%$ by HPLC analysis. The compound was dissolved in dimethyl sulfoxide (DMSO, Solarbio Science \& Technology Co, Ltd). Its structure is illustrated in Figure 1.

\section{Cell culture and treatments}

Human hepatocarcinoma cells (SMMC-7721 and Hep3B2.1-

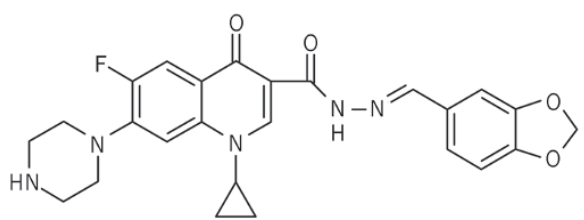

Figure 1. Structure of 1-cyclopropyl-6-fluoro-4-oxo-7-piperazin-1-yl-1,4dihydro-quinoline-3-carboxylic acid benzo[1,3]dioxol-5-ylmethylenehydrazide (QNT4).
7), human breast adenocarcinoma cells (MCF-7), and human colon adenocarcinoma cells (HCT-8), obtained from the Cell Bank of the Chinese Academy of Sciences, Shanghai, were cultured in DMEM medium (Gibco BRL, USA) supplemented with 10\% heat-inactivated fetal bovine serum (Sijiqing Co, Ltd, Hangzhou, China), $100 \mathrm{IU} / \mathrm{mL}$ penicillin, and $100 \mu \mathrm{g} / \mathrm{mL}$ streptomycin. The cells were maintained in $5 \% \mathrm{CO}_{2}$ at $37^{\circ} \mathrm{C}$. When the cells reached approximately 50\%-70\% confluence, they were treated with different amounts of chemicals as indicated. DMSO was used as the vehicle control.

\section{MTT assay}

The cells were seeded at a density of $1 \times 10^{4}$ cells $/ \mathrm{mL}$ in 96-well culture plates. After $24 \mathrm{~h}$, the cells were treated with the indicated concentrations of QNT4 or ciprofloxacin. Control wells consisted of cells incubated with medium only. After 24, 48, and $72 \mathrm{~h}$ of treatment, cells were incubated with $20 \mu \mathrm{L}$ MTT (5 $\mathrm{mg} / \mathrm{mL}$, 3-[4,5-dimethylthiazol-2-yl]-2,5-diphenyltetrazolium bromide; Sigma, St Louis, MO, USA). After $4 \mathrm{~h}$ at $37^{\circ} \mathrm{C}$, the supernatant was removed, and $150 \mu \mathrm{L}$ DMSO was added. After the blue crystals were dissolved in DMSO, the optical density $(O D)$ was detected at a wavelength of $570 \mathrm{~nm}$ using a 96-well multiscanner autoreader (Bio-Rad, USA). The following formula was used: cell proliferation inhibited $(\%)=[1-(O D$ of the experimental samples/OD of the control) $] \times 100$. The $\mathrm{IC}_{50}$ is defined as the concentration at which cell proliferation is inhibited by $50 \%$.

\section{Hoechst 33258 staining}

SMMC-7721 cells were seeded at a density of $1 \times 10^{4}$ cells $/ \mathrm{mL}$ on the glass cover slides of a 35-mm chamber. After being treated with QNT4 for $24 \mathrm{~h}$, the cells were washed twice with PBS and incubated with $5 \mu \mathrm{g} / \mathrm{mL}$ Hoechst 33258 (Sigma, St Louis, MO, USA) for $10 \mathrm{~min}$ at $37^{\circ} \mathrm{C}$ in the dark. The cells were then washed and fixed with $4 \%$ paraformaldehyde in PBS for $5 \mathrm{~min}$ at $4{ }^{\circ} \mathrm{C}$. Nuclear morphology was then examined under a fluorescent microscope (BX51, Olympus, Japan).

\section{TUNEL assay}

Cells $\left(1 \times 10^{4}\right.$ cells $\left./ \mathrm{mL}\right)$ were seeded in growth medium on the glass cover slides of 6-well plates for overnight incubation. They were then treated with the indicated concentrations of QNT4 for $24 \mathrm{~h}$. Control wells consisted of cells incubated with medium only. Next, cells were examined for apoptosis by terminal deoxynucleotidyl transferase-mediated dUTP nickend labeling (TUNEL) assay (Promega, Madison, WI, USA), according to the manufacturer's instructions. Cells were visualized and photographed from at least five randomly chosen areas in each slide, using a fluorescent microscope (BX51, Olympus, Japan). Percent apoptosis was determined by counting the number of apoptotic cells and dividing by the total number of cells in the areas.

\section{DNA agarose gel electrophoresis}

Cells were treated with media containing different concentrations of QNT4 for $24 \mathrm{~h}$ and were then washed twice with PBS. 
The chromosomal DNA was extracted with the Apoptotic DNA Ladder Detection Kit (Beyotime, China) according to the manufacturer's instructions. The DNA sample was incubated at $37^{\circ} \mathrm{C}$ for $30 \mathrm{~min}$ and electrophoresed at $40 \mathrm{~V} / \mathrm{cm}$ on a $1 \%$ agarose gel containing $1 \mathrm{mg} / \mathrm{mL}$ ethidium bromide. Finally, the apoptotic DNA fragments were visualized under a UV transilluminator and photographed.

\section{Topoisomerase II-mediated supercoiled pBR322 DNA relaxation} assay

DNA topoisomerase II activity was determined by the supercoiled pBR322 DNA relaxation assay ${ }^{[13]}$. The experiments were performed by incubating human topoisomerase IIa (Sigma, St Louis, MO, USA) with $1 \mu \mathrm{g}$ supercoiled pBR322 DNA in $5 \mu \mathrm{L}$ relaxation buffer $(200 \mathrm{mmol} / \mathrm{L}$ Tris- $\mathrm{HCl}, \mathrm{pH}$ 7.5, $340 \mathrm{mmol} / \mathrm{L}$ $\mathrm{KCl}, 40 \mathrm{mmol} / \mathrm{L} \mathrm{MgCl}_{2}, 20 \mathrm{mmol} / \mathrm{L} \mathrm{DTT}, 120 \mathrm{mg} / \mathrm{L} \mathrm{BSA}, 5$ mmol/L EDTA, $4 \mathrm{mmol} / \mathrm{L} \mathrm{ATP)}$ under increasing concentrations of QNT4. In this experiment, etoposide (Sigma, St Louis, MO, USA), a known topoisomerase II poison ${ }^{[14]}$, was used as a positive control. The mixture was incubated at $37^{\circ} \mathrm{C}$ for 30 min and the reaction was terminated by adding $20 \mu \mathrm{L} 10 \%$ SDS and $1 \mu \mathrm{L}$ protease $\mathrm{K}\left(1 \times 10^{4} \mathrm{mg} / \mathrm{L}\right)$. Samples were subjected to electrophoresis in $1 \%$ agarose gels. DNA was then stained with $1 \mathrm{mg} / \mathrm{mL}$ ethidium bromide and photographed under a UV transilluminator.

\section{Estimate of mitochondrial membrane potential loss}

Cells were treated with media containing different concentrations of QNT4 for $24 \mathrm{~h}$ and were then incubated with 0.5 $\mathrm{mg} / \mathrm{mL}$ of the fluorescence probe JC-1 (5,5',6,6'-tetrachloro-1, 1',3,3' - tetraethyl-benzimidazolcarbocyanine iodide, Beyotime, China) at $37^{\circ} \mathrm{C}$ for $20 \mathrm{~min}$. The cells were thoroughly washed twice with buffer and incubated with $5 \mu \mathrm{g} / \mathrm{mL}$ Hoechst 33258 for $10 \mathrm{~min}$ in the dark. After two additional washes, the mitochondrial membrane potential $(\Delta \psi \mathrm{m})$ was measured by a high content screening imaging system (Thermo Fisher Scientific, USA).

\section{Western blotting assay}

After treatment with different concentrations of QNT4 for $24 \mathrm{~h}$, cells were lysed with ice-cold RIPA lysis buffer. Protein concentrations were determined using the Bradford method. Samples were separated by $12 \%$ SDS-PAGE under reducing conditions and transferred onto polyvinylidene fluoride (PVDF) membranes (Millipore). The membranes were blocked with $5 \%$ non-fat milk in TBST buffer $(20 \mathrm{mmol} / \mathrm{L}$ Tris$\mathrm{HCl}, 137 \mathrm{mmol} / \mathrm{L} \mathrm{NaCl}$, and $0.1 \%$ Tween 20, $\mathrm{pH} \mathrm{8.0)} \mathrm{for} 1 \mathrm{~h}$ at room temperature, prior to an overnight incubation at $4{ }^{\circ} \mathrm{C}$ with specific antibodies to caspase-9, caspase-8, caspase-3, p53, $\mathrm{Bcl}-2$, Bax, cytochrome $c$, or $\beta$-actin (all antibodies from Santa Cruz Biotechnology, USA). The membranes were washed and incubated with horseradish peroxidase conjugated anti-mouse IgG (Beijing ZhongShan GoldenBridge Biological Technology Co, LTD), or anti-rabbit IgG (Beyotime, China) secondary antibodies for $1 \mathrm{~h}$. Once again, the membranes were washed three times with TBST, and the proteins were detected using an enhanced chemiluminescence substrate (ECL, Beyotime, China).

Cytochrome $c$ release from mitochondria was evaluated by Western blotting analysis of cytosolic protein samples. Cytosolic protein fractions were prepared using the cell mitochondria isolation kit (Beyotime, China).

\section{Statistical analyses}

The data are presented as the mean $\pm S D$ for the indicated number of independent experiments. Statistical significance was calculated using the $t$-test for paired samples. $P<0.05$ was regarded as significant and $P<0.01$ as highly significant.

\section{Results \\ QNT4 suppressed the growth of cancer cells in vitro}

The cytotoxicity of QNT4 against cancer cells was assessed using the MTT cell viability assay. The cells were treated with various concentrations of QNT4 for 24, 48, and $72 \mathrm{~h}$, resulting in a significant decrease in cell viability in a dose- and time-dependent manner (Figure 2). Within the three cancer cell lines used in this experiment, QNT4 was most effective against SMMC-7721. As shown in Figure2A, the $\mathrm{IC}_{50}$ values after treatment for 24,48 , and $72 \mathrm{~h}$ were $2.956 \pm 0.024 \mu \mathrm{mol} / \mathrm{L}$ $\left(r^{2}=0.9521\right), 3.497 \pm 0.063 \mu \mathrm{mol} / \mathrm{L}\left(r^{2}=0.8382\right)$, and $3.345 \pm 0.039$ $\mu \mathrm{mol} / \mathrm{L}\left(r^{2}=0.9700\right)$, respectively. For MCF-7 cells, the $\mathrm{IC}_{50}$ values after treatment for 24,48 , and $72 \mathrm{~h}$ were $3.710 \pm 0.027$ $\mu \mathrm{mol} / \mathrm{L}\left(r^{2}=0.8764\right), 3.377 \pm 0.021 \mu \mathrm{mol} / \mathrm{L}\left(r^{2}=0.9438\right)$ and $4.299 \pm 0.029 \mu \mathrm{mol} / \mathrm{L}\left(r^{2}=0.8857\right)$, respectively. For the HCT-8 cells, the $\mathrm{IC}_{50}$ values after treatment for 24,48 , and $72 \mathrm{~h}$ were $3.694 \pm 0.030 \mu \mathrm{mol} / \mathrm{L}\left(r^{2}=0.8750\right), 4.568 \pm 0.018 \mu \mathrm{mol} / \mathrm{L}$ $\left(r^{2}=0.8330\right)$, and $4.318 \pm 0.025 \mu \mathrm{mol} / \mathrm{L}\left(r^{2}=0.8096\right)$, respectively. In contrast, ciprofloxacin showed weak cytotoxicity against SMMC-7721 cells (Figure 2D). The $\mathrm{IC}_{50}$ value at $48 \mathrm{~h}$ treatments was $6.860 \pm 0.194 \mu \mathrm{mol} / \mathrm{L}\left(r^{2}=0.8039\right)$.

\section{QNT4-induced apoptosis of SMMC-7721 cells}

After treatment with various concentrations of QNT4 for $24 \mathrm{~h}$, marked morphological changes indicative of cell apoptosis, such as chromatin condensation and nuclear fragmentation, were clearly observed for SMMC-7721 cells following Hoechst 33258 staining (Figure 3, Table 1).

The integrity of DNA was assessed by agarose gel electrophoresis. As shown in Figure 4, 24 h incubation of SMMC7721 cells with $2.964 \mu \mathrm{mol} / \mathrm{L}$ and $4.600 \mu \mathrm{mol} / \mathrm{L}$ QNT4 elicited characteristic DNA "ladder" bands indicative of apoptotic

Table 1. Apoptotic effects of QNT4 on SMMC-7721 cells. $n=6$. Mean \pm SD. ${ }^{\mathrm{b}} \mathrm{P}<0.05$ vs control. $T=2.57$.

\begin{tabular}{lccc}
\hline & Total cells & Apoptotic cells & $\begin{array}{c}\text { Apoptosis } \\
\text { ratio/\% }\end{array}$ \\
\hline Control & $352 \pm 12.1$ & $21.42 \pm 2.6$ & $0.6 \pm 0.1$ \\
QNT4 $(2.146 \mu \mathrm{mol} / \mathrm{L})$ & $259.31 \pm 10.2$ & $30.11 \pm 2.28$ & $11.6 \pm 1.8$ \\
QNT4 $(2.964 \mu \mathrm{mol} / \mathrm{L})$ & $212.18 \pm 8.6$ & $42.18 \pm 3.2$ & $19.9 \pm 2.8^{b}$ \\
QNT4 $(4.600 \mu \mathrm{mol} / \mathrm{L})$ & $160.78 \pm 2.9$ & $53.44 \pm 6.2$ & $33.2 \pm 3.9^{b}$ \\
\hline
\end{tabular}



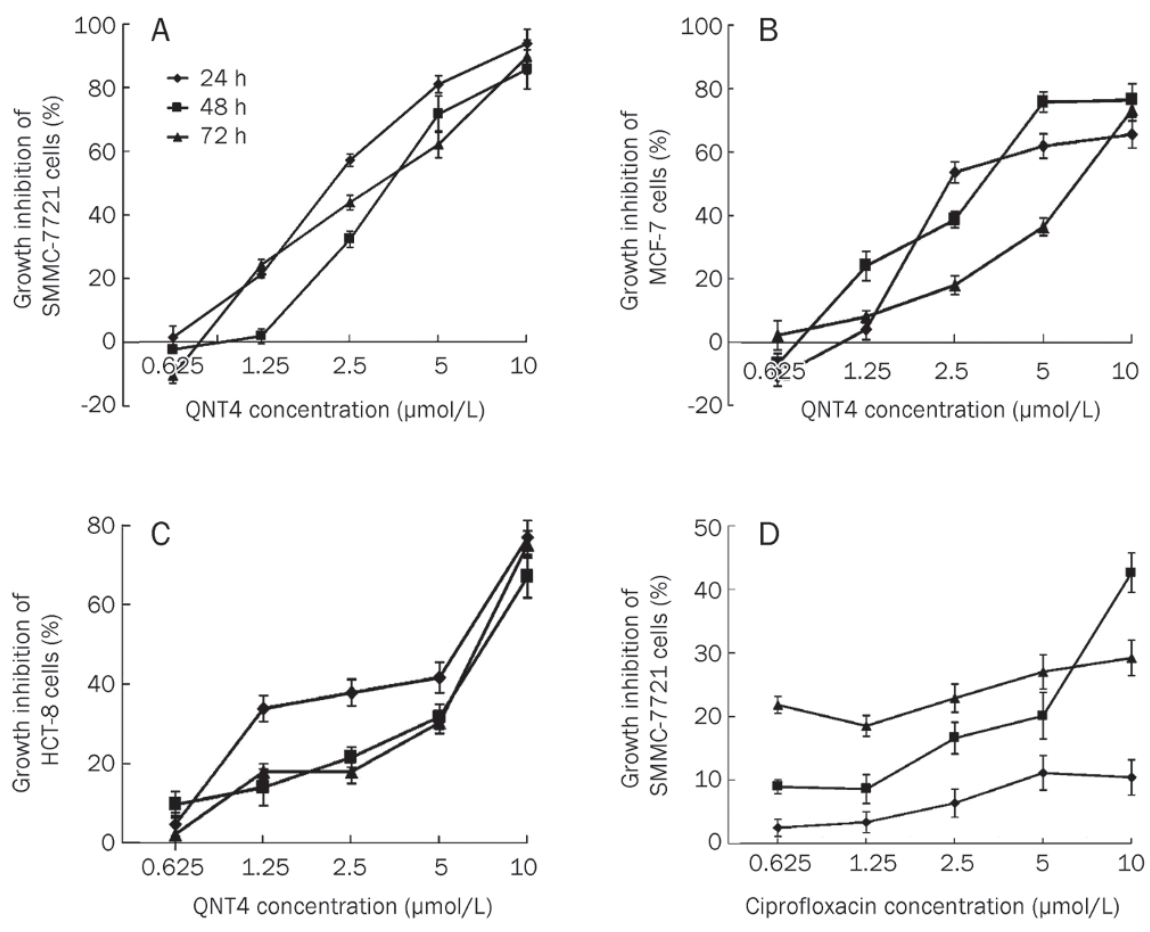

Figure 2. Dose- and time-dependent growth inhibition of the cancer cells by QNT4 or ciprofloxacin. (A) SMMC-7721 cells were treated with various concentration of QNT4. (B) MCF-7 cells were treated with various concentration of QNT4. (C) HCT-8 cells were treated with various concentration of QNT4. (D) SMMC-7721 cells were treated with various concentration of ciprofloxacin. Data represent means $\pm S D$ of three independent measurements.
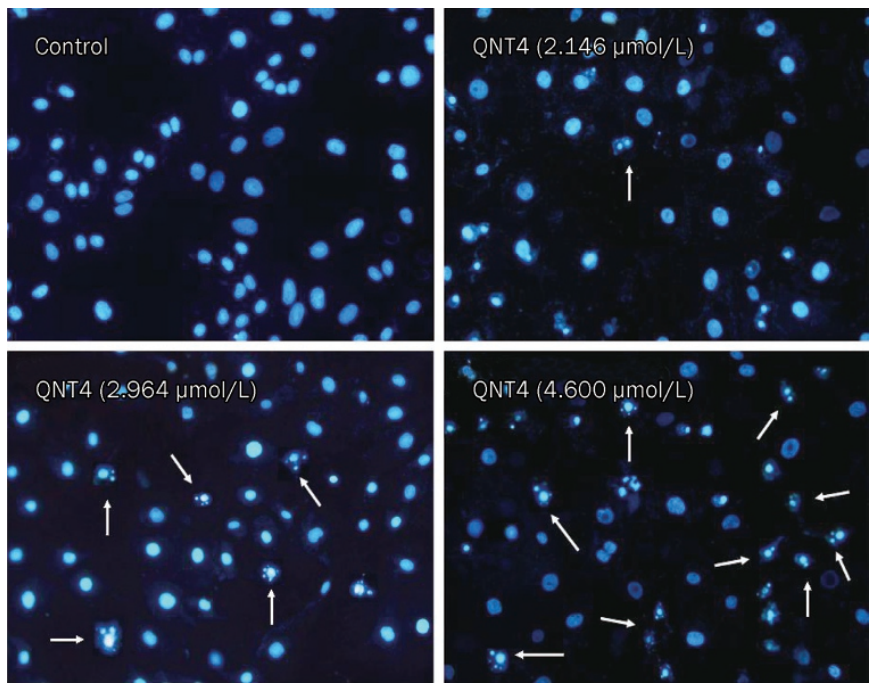

Figure 3. QNT4 induced morphological changes of SMMC-7721 cells. Cells were treated with 0, 2.146 ( $\left(\mathrm{C}_{30}\right.$ group), 2.964 (IC $\mathrm{C}_{50}$ group), and 4.600 $\mu \mathrm{mol} / \mathrm{L}$ (IC $\mathrm{C}_{90}$ group) QNT4, respectively for $24 \mathrm{~h}$. Morphological changes were examined by staining with Hoechst 33258, and the images were observed and photographed under a fluorescence microscope. $\times 400$. Arrows indicate apoptotic cells.

internucleosomal DNA fragmentation (approximately 180-200 $\mathrm{bp})$.

To further investigate the role of QNT4 in apoptosis, TUNEL assay was performed. As shown in Figure 5 and Table 2, $24 \mathrm{~h}$ incubation with QNT4 increased the percentage of apoptotic SMMC-7721 cells in a concentration-dependent manner.
Table 2. Apoptotic effects of QNT4 on SMMC-7721 cells. $n=6$. Mean \pm SD. ${ }^{\mathrm{b}} P<0.05$ vs control. $T=2.46$. ${ }^{\mathrm{C}} P<0.01$ vs control. $T=3.84$.

\begin{tabular}{lccc}
\hline & Total cells & Apoptotic cells & $\begin{array}{c}\text { Apoptosis } \\
\text { ratio/\% }\end{array}$ \\
\hline Control & $320.21 \pm 12.65$ & $12.74 \pm 4.25$ & $5.31 \pm 2.10$ \\
QNT4 $(2.146 \mu \mathrm{mol} / \mathrm{L})$ & $256.44 \pm 12.07$ & $33.40 \pm 5.54$ & $19.13 \pm 4.09^{\mathrm{b}}$ \\
QNT4 $(2.964 \mu \mathrm{mol} / \mathrm{L})$ & $180.38 \pm 15.04$ & $37.54 \pm 8.25$ & $28.49 \pm 2.18^{\mathrm{c}}$ \\
QNT4 $(4.600 \mu \mathrm{mol} / \mathrm{L})$ & $109.54 \pm 11.40$ & $45.45 \pm 6.40$ & $45.94 \pm 4.75^{\mathrm{c}}$ \\
\hline
\end{tabular}

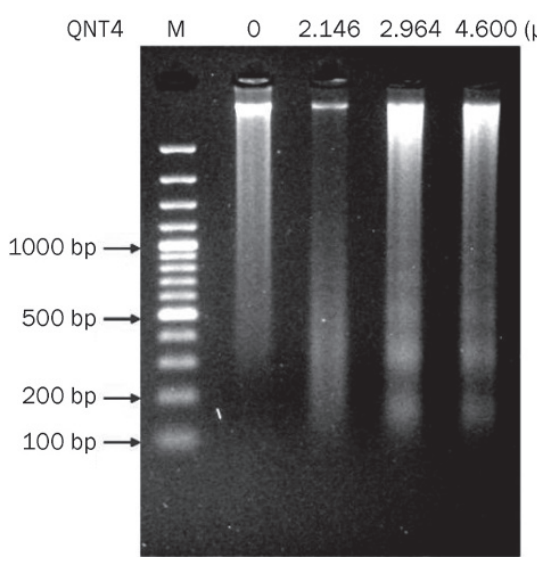

Figure 4. DNA fragmentation in SMMC-7721 cells. SMMC-7721 cells treated with $0,2.146,2.964$, and $4.600 \mu \mathrm{mol} / \mathrm{L}$ QNT4, respectively for $24 \mathrm{~h}$. DNA from $1 \times 10^{6}$ cells was electrophoresed through $1 \%$ agarose gels and stained with $0.5 \mu \mathrm{g} / \mathrm{mL}$ ethidium bromide. Lane $\mathrm{M}$ was standard marker of DNA ladder. 

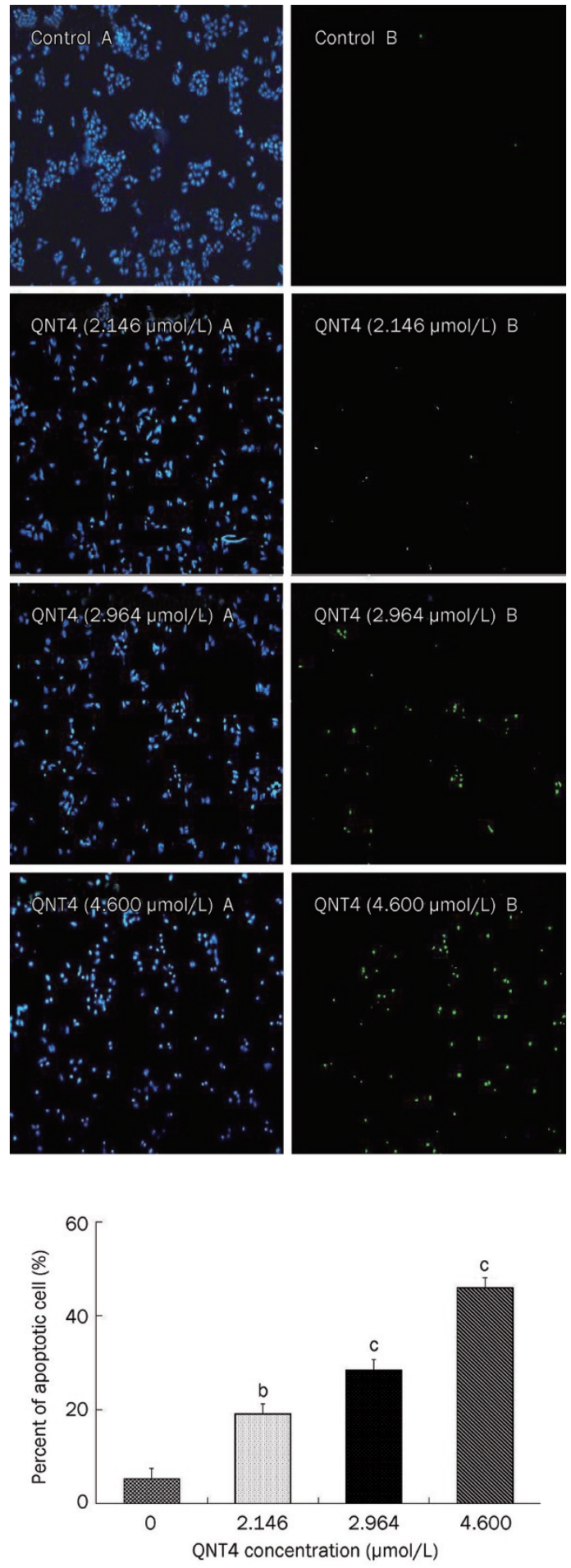

Figure 5. Induction of apoptosis in SMMC-7721 cells treated with QNT4 for $24 \mathrm{~h}$ was evaluated by TUNEL assay. Representative images were taken with nuclear stain (DAPI, A) and apoptosis stain (TUNEL, B). $\times 200$. ${ }^{\mathrm{b}} P<0.05,{ }^{\mathrm{c}} P<0.01$ vs control $(0 \mu \mathrm{mol} / \mathrm{L})$.

The effect of QNT4 on the catalytic activities of eukaryotic topoisomerase II

In this experiment, relative double-stranded DNA cleavage/ religation was determined using agarose gel electrophoresis of treated-pBR322 DNA and nontreated-pBR322 DNA (Figure 6). QNT4 decreased the amount of supercoiled DNA (Form I), while increasing nicked circular plasmid molecules (Form II) and linear molecules (Form III) in a dose-dependent manner. The effects of QNT4 on topoisomerase II-mediated DNA cleavage/religation were similar to that of etoposide. This suggests that QNT4 increased topoisomerase II-mediated DNA breaks while inhibiting DNA religation.

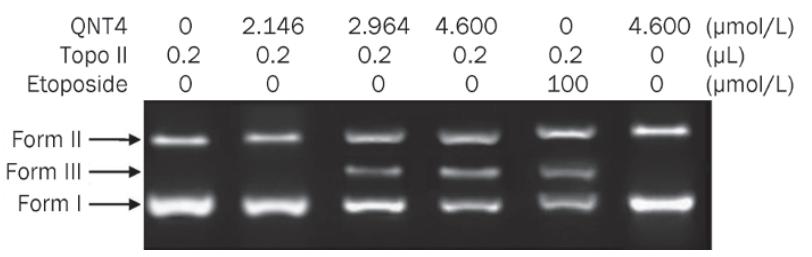

Figure 6. The inhibitory effects of QNT4 on DNA topoisomerase II activity. Human topoisomerase Il $\alpha$ was incubated with supercoiled pBR322 DNA in relaxation buffer under increasing concentrations of QNT4. Samples were subjected to electrophoresis in $1 \%$ agarose gels and then stained with ethidium bromide and photographed under a UV transilluminator.

The effect of QNT4 on the mitochondrial membrane potential Mitochondrial membrane potential $(\Delta \psi \mathrm{m})$ was detected with the fluorescent probe JC-1, which exists predominantly in monomeric form in cells with depolarized mitochondria and displays green fluorescence at $490 \mathrm{~nm}$. In contrast, JC-1 primarily forms aggregates in cells with polarized mitochondria and shows reddish-orange fluorescence. The emission intensity ratio of the $545 \mathrm{~nm}$ and $595 \mathrm{~nm}$ peaks was used as a measure of mitochondrial depolarization; a higher ratio indicated more depolarization. QNT4 treatment of SMMC-7721 cells for $24 \mathrm{~h}$ resulted in green JC-1 fluorescence in a dosedependent manner, which is consistent with a loss of $\Delta \psi \mathrm{m}$ (Figure 7). After treatment with QNT4 at $2.146 \mu \mathrm{mol} / \mathrm{L}, 2.964$ $\mu \mathrm{mol} / \mathrm{L}$, and $4.600 \mu \mathrm{mol} / \mathrm{L}$ for $24 \mathrm{~h}$, cellular $\Delta \psi \mathrm{m}$ decreased to $(8.74 \pm 3.62) \%$, (39.64 \pm 4.52$) \%$, and $(46.90 \pm 3.29) \%$, respectively, compared to the control $(P<0.05, T=3.12)$.

The effect of QNT4 on apoptotic protein expression in SMMC7721 cells

To characterize the signaling pathways involved in QNT4induced apoptosis, the expression levels of p53, Bcl-2, Bax, caspase-9, caspase-8, and caspase-3 in QNT4-treated SMMC-7721 cells were analyzed by Western blotting (Figure 8). Mitochondrial release of cytochrome $c$ is a critical step in the apoptotic cascade that can activate downstream caspases. To examine whether QNT4-induced apoptosis in SMMC-7721 cells was associated with the release of cytochrome $c$ from mitochondria, the levels of cytochrome $c$ in both the cytosolic and mitochondrial fractions were analyzed. The results showed that there was a significant increase of cytochrome $c$ in the cytosol and a decrease in the mitochondrial fraction after $24 \mathrm{~h}$ treatment with QNT4 (Figure 9).

As a tumor suppressor protein, p53 can induce cell apop- 

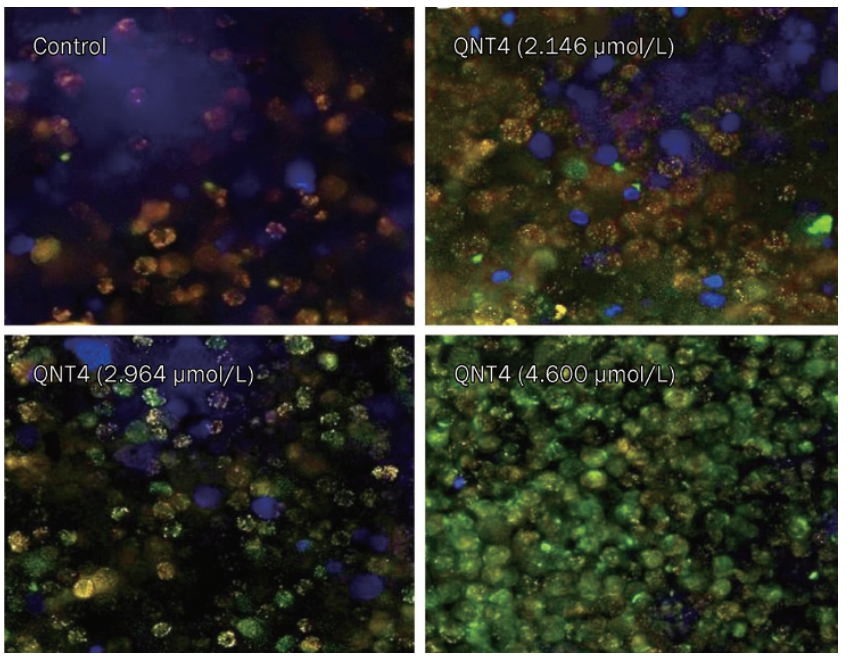

Figure 7. HCS analysis after JC-1 staining to detect changes in the mitochondrial membrane potential of SMMC-7721 cells induced by QNT4. Cells were treated with 0, 2.146 ( IC $_{30}$ group), 2.964 (IC ${ }_{50}$ group), and 4.600 $\mu \mathrm{mol} / \mathrm{L}$ ( $\mathrm{IC}_{90}$ group) QNT4, respectively for $24 \mathrm{~h}$. The mitochondrial membrane potential $(\Delta \psi \mathrm{m})$ was measured by high content screening image system.
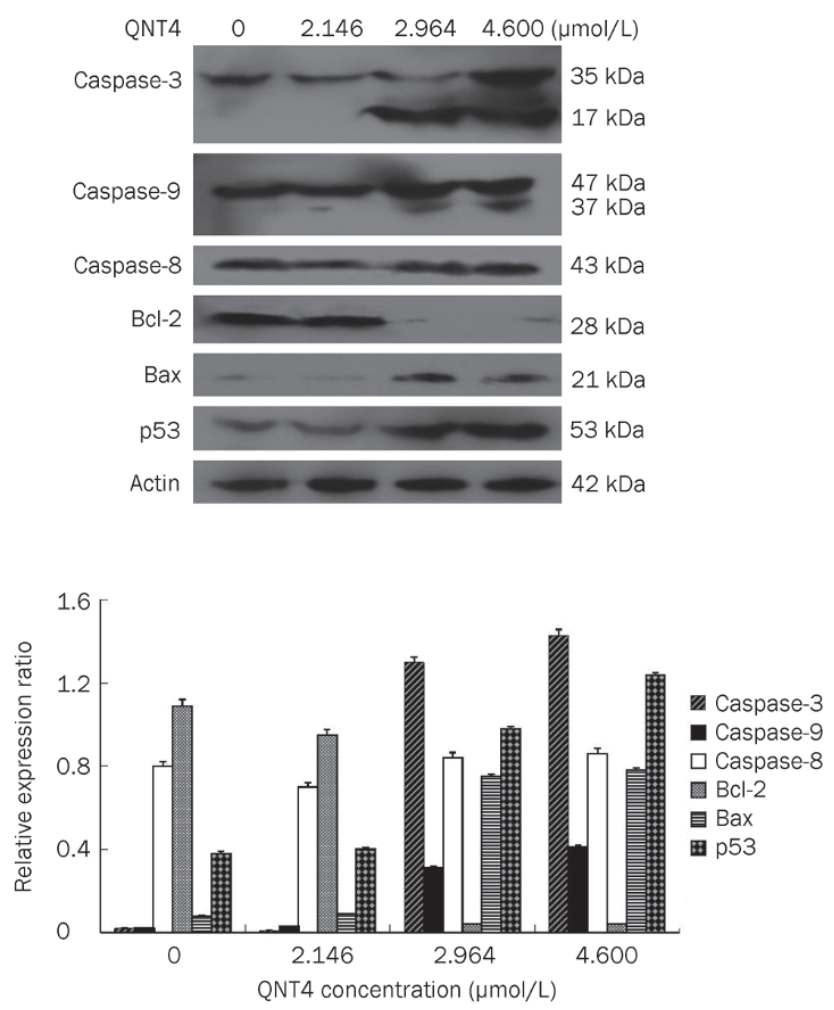

Figure 8. Protein expressions levels of caspase-9, caspase-8, caspase-3, $\mathrm{Bcl}-2$, Bax, and p53 were examined by Western blot analysis in SMMC7721 cells after treatment with $0,2.146$ (IC 30 group), 2.964 (IC 50 group), and $4.600 \mu \mathrm{mol} / \mathrm{L}$ (IC 90 group) QNT4, respectively for $24 \mathrm{~h}$.
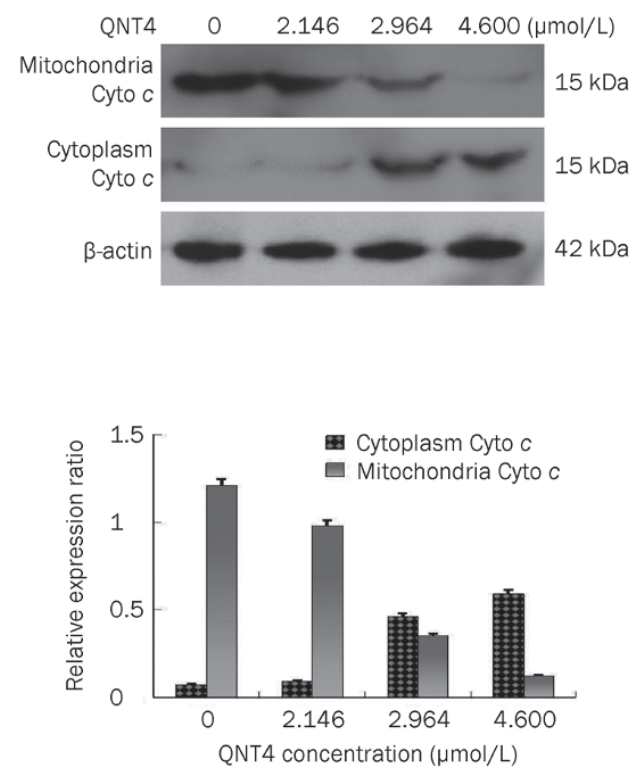

Figure 9. The effect of QNT4 on the release of cytochrome c from mitochondria to the cytosol were examined by Western blot analysis in SMMC7721 cells after treatment with $0,2.146$ ( $\mathrm{IC}_{30}$ group), 2.964 (IC 50 group), and $4.600 \mu \mathrm{mol} / \mathrm{L}\left(\mathrm{IC}_{90}\right.$ group) QNT4, respectively for $24 \mathrm{~h}$.

tosis in response to stress signals, such as DNA damage. The expression of p53 protein was induced by various concentrations of QNT4 treatment. The anti-apoptotic protein Bcl-2 was also decreased, while the pro-apoptotic protein Bax was increased dramatically by QNT4 treatment. Because changes in Bax/Bcl-2 levels during the initiation of caspase signaling have been reported, caspase- 9 and caspase- 3 activation was examined in this study as well. Upon apoptotic stimulation, full-length caspase- 9 and caspase- 3 were cleaved into active fragments. QNT4 treatment $(2.964 \mu \mathrm{mol} / \mathrm{L}$ and 4.600 $\mu \mathrm{mol} / \mathrm{L})$ significantly increased the cleaved, activated forms of caspase-9 and caspase-3. These results indicate that QNT4 induced apoptosis in SMMC-7721 cells through the intrinsic mitochondrial apoptotic pathway. On the other hand, QNT4 did not affect the expression of caspase-8, regardless of the treatment dose. Caspase- 8 is a prominent initiator of death receptors and is activated by death receptor apoptosis stimuli. Therefore, it seems that QNT4 enhanced apoptosis through the intrinsic mitochondrial apoptosis pathway, whereas the deathreceptor signaling pathway played a less important role.

\section{Discussion}

Fluoroquinolone compounds have been reported to have an inhibitory effect on cell proliferation and can induce apoptosis in carcinoma cell lines ${ }^{[15,16]}$. In this study, MTT assays indicated that QNT4 inhibited the proliferation of human hepatocarcinoma SMMC-7721 cells in a dose- and time-dependent manner. Thus, we propose that QNT4 could be an effective candidate for therapy against malignant tumors.

Antibacterial fluoroquinolones are a class of antibacterial 
agents that are commonly used to treat human and animal infections. The treatment of bacterial infection inhibits bacterial DNA gyrase by a mechanism similar to that of certain antitumor drugs against mammalian topoisomerase $\mathrm{II}^{[17]}$. Some antibacterial fluoroquinolones, such as ciprofloxacin, ofloxacin and norfloxacin, also demonstrate a slight interaction with mammalian topoisomerase II, although these antibacterials are much more selective for bacterial DNA gyrase ${ }^{[18]}$. However, a number of chemically modified antibacterial fluoroquinolone derivatives with enhanced activity against mammalian topoisomerase II have been developed. Strong inhibitory effects against eukaryotic DNA replication were demonstrated, and their structure-activity relationship have also been characterized ${ }^{[19]}$. These fluoroquinolone derivatives share a similar mechanism of action with several clinically relevant antitumor agents, such as ellipticine and etoposide. They bind to the topoisomerase II-DNA cleavage complexes, thus converting topoisomerase II into a physiological toxin that creates protein-linked DNA breaks in the genome of treated cells ${ }^{[20]}$. As shown in Figure 6, QNT4 increased topoisomerase II-mediated supercoiled pBR322 DNA breaks but inhibited topoisomerase II-mediated DNA religation. The effects of QNT4 on the topoisomerase II-mediated DNA cleavage/religation were similar to that of etoposide. These findings provide evidence that QNT4 is a poisonous inhibitor for topoisomerase $\mathrm{II}^{[21]}$. QNT4 binds the reversible complex between DNA and topoisomerase II, preventing the dissociation of the DNA-topoisomerase II complex and thereby inducing DNA damage ${ }^{[22,23]}$. It has been reported that one of the key responses of fluoroquinolone-induced DNA damage is the expression of tumor suppressor protein p53, causing apoptosis of the treated cells ${ }^{[24,25]}$. The results of this study showed that QNT4 induced cell apoptosis, which was accompanied by the up-regulation of p53 protein level in a dose-dependent manner, suggesting that the activation of the p53 pathway may be involved in the apoptotic process of SMMC-7721 cells.

Apoptosis may be initiated by the stimulation of death receptors located on the cell surface or through an intrinsic pathway involving the release of apoptotic signals from mitochondria ${ }^{[26,27]}$. The cascading activation of caspases and the release of cytochrome $c$ from the mitochondria play key roles in apoptosis, and the type of intracellular apoptotic pathways involved may be deduced from the activated initiator caspases. We specifically investigated the mitochondria-related events during apoptosis, such as the breakdown of the mitochondrial membrane, the expression of Bax and Bcl-2, and the activation of caspase 9. Members of the Bcl-2 protein family play an important role in apoptosis by regulating the release of cytochrome $c$ from the mitochondria to the cytosol ${ }^{[28]}$. It has been shown that anti-apoptotic proteins, such as Bcl-2 and Bcl-XL, inhibit cytochrome $c$ release whereas pro-apoptotic members, such as Bax, promote cytochrome $c$ release, leading to the initiation of apoptosis. Here, we observe that QNT4 mediated an up-regulation of Bax and down-regulation of Bcl-2 to induce apoptosis, possibly through increased caspase activity and by preventing the formation of anti-apoptotic bodies. Therefore, it is possible that QNT4 induced the opening of the mitochondrial permeability transition pore through the up-regulation of Bax, resulting in the release of cytochrome $c^{[29,30]}$. In fact, we observed a QNT4-induced decrease of the mitochondrial membrane potential in SMMC-7721 cells, followed by increased cytochrome $c$ release from the mitochondria into the cytosol. In the mitochondrial apoptotic pathway, the release of cytochrome $c$ is a critical event because cytochrome $c$ forms a complex with procaspase-9 in the cytoplasm (resulting in the activation of procaspase-9), which will eventually lead to the activation of caspases 3 and the induction of apoptosis ${ }^{[31]}$. Because activated caspase 8 , activated by the death receptor, is able to cleave the proapoptotic Bcl-2 family member and then trigger a distinct apoptotic pathway involving mitochondria in some fluoroquinolone compound-treated cell types, it is possible that the activation of caspase 9 in QNT4-treated SMMC7721 cells may be due to the activation of the death receptorcaspase 8 pathway ${ }^{[32,33]}$. We showed that the cleavage of caspase 8 was not evident in QNT4-treated cells. Therefore, it is unlikely that the activation of caspase 9 is triggered mainly by the caspase 8 pathway, although this possibility cannot be excluded in other cell types ${ }^{[34]}$. Thus, we conclude that QNT4 induces apoptosis predominantly through the mitochondrial pathway.

In summary, these data have established QNT4 as a fluoroquinolone derivative that exerts potent anticancer activity through the mechanism of eukaryotic topoisomerase II poisoning. QNT4 also inhibited the proliferation of SMMC-7721 cells through DNA damage and up-regulation of the p53 protein. In addition, QNT4 caused mitochondrial dysfunction, accompanied by an increase in Bax protein expression, a loss of the mitochondrial membrane potential, and the cytoplasmic release of cytochrome $c$. The subsequent activation of caspase cascades plays a critical role in QNT4-induced apoptosis in human hepatocarcinoma SMMC-7721 cells. Most fluoroquinolone agents can reach concentrations that are far above serum levels in solid tissues, such as the liver ${ }^{[33]}$. QNT4 may, therefore, have a potential use as a novel chemotherapeutic agent in the treatment of liver cancer, as well as other solid cancers. The use of QNT4 as a modulating agent may also be interesting in combination with anticancer drugs for future preclinical and clinical studies.

\section{Acknowledgements}

This work was supported by the National Natural Science Foundation of China (20872028 and 31070952). We are grateful to Prof Jie-xin DENG (Henan University, China) for his critical comments and English revision of the manuscript.

\section{Author contribution}

Guo-qiang HU and Bin LIU contributed to the research design; Zhen-yu SHI, Yong-qiang LI, and YU-hua KANG performed the research; Jin-bo DENG and Chao-shen HUANGFU contributed new reagents and analytical tools; Yong-qiang LI analyzed the data; Yong-qiang LI and Bin LIU wrote the manuscript. 
alpha by selective mutagenesis. J Mol Biol 2000; 300: 481-91.

\section{References}

1 Bolon MK. The newer fluoroquinolones. Infect Dis Clin North Am 2009; 23: 1027-51.

2 Bax BD, Chan PF, Eggleston DS, Fosberry A, Gentry DR, Gorrec F, et al. Type IIA topoisomerase inhibition by a new class of antibacterial agents. Nature 2010; 466: 935-40.

3 Rajabalian S, Foroumadi A, Shafiee A, Emami S. Functionalized N-(2oxyiminoethyl) piperazinyl quinolones as new cytotoxic agents. J Pharm Pharm Sci 2007; 10: 153-8.

4 Yamashita Y, Ashizawa T, Morimoto M, Hosomi J, Nakano H. Antitumor quinolones with mammalian topoisomerase II mediated DNA cleavage activity. Cancer Res 1992; 52: 2818-22.

5 Kamat AM, DeHaven JI, Lamm DL. Quinolone antibiotics: a potential adjunct to intravesical chemotherapy for bladder cancer. Urology 1999; 54: 56-61.

6 Koziel R, Szczepanowska J, Magalska A, Piwocka K, Duszynski J, Zablocki K. Ciprofloxacin inhibits proliferation and promotes generation of aneuploidy in Jurkat cells. J Physiol Pharmacol 2010; 61: 233-9.

7 Hawtin RE, Stockett DE, Byl JA, McDowell RS, Nguyen T, Arkin MR, et al. Voreloxin is an anticancer quinolone derivative that intercalates DNA and poisons topoisomerase II. PLoS One 2010; 5: e10186.

8 Foroumadi A, Emami S, Rajabalian S, Badinloo M, Mohammadhosseini $\mathrm{N}$, Shafiee A. N-Substituted piperazinyl quinolones as potential cytotoxic agents: structure-activity relationships study. Biomed Pharmacother 2009; 63: 16-20.

9 Chang YH, Hsu MH, Wang SH, Huang $\sqcup$, Qian K, Morris-Natschke SL, et al. Design and synthesis of 2-(3-benzo[b]thienyl)-6,7-methylenedioxyquinolin-4-one analogues as potent antitumor agents that inhibit tubulin assembly. J Med Chem 2009; 52: 4883-91.

10 You QD, Li ZY, Huang CH, Yang Q, Wang XJ, Guo QL, et al. Discovery of a novel series of quinolone and naphthyridine derivatives as potential topoisomerase I inhibitors by scaffold modification. J Med Chem 2009; 52: 5649-61.

11 Hu GQ, Wu XK, Wang X, Zhang ZQ, Xie SQ, Huang WL, et al. Synthesis and antitumor activity of $\mathrm{C} 3$ heterocyclic-substituted fluoroquinolone derivatives (I): ciprofloxacin aminothiodiazole Schiff-bases. Acta Pharm Sin 2008, 43: 1112-5.

12 Kumar D, Sundaree S, Johnson EO, Shah K. An efficient synthesis and biological study of novel indolyl-1,3,4-oxadiazoles as potent anticancer agents. Bioorg Med Chem Lett 2009; 19: 4492-4.

13 Robinson MJ, Martin BA, Gootz TD, McGuirk PR, Moynihan M, Sutcliffe $J A$, et al. Effects of quinolone derivatives on eukaryotic topoisomerase II. A novel mechanism for enhancement of enzyme-mediated DNA cleavage. J Biol Chem 1991; 266: 14585-92.

14 Pommier $\mathrm{Y}$, Leo E, Zhang $\mathrm{H}$, Marchand $\mathrm{C}$. DNA topoisomerases and their poisoning by anticancer and antibacterial drugs. Chem Biol 2010; 17: 421-33.

15 Efthimiadou EK, Thomadaki H, Sanakis Y, Raptopoulou CP, Katsaros N, Scorilas A, et al. Structure and biological properties of the copper (II) complex with the quinolone antibacterial drug N-pro-pyl-norfloxacin and 2,2'-bipyridine. J Inorg Biochem 2007; 101: 64-73.

16 DoganKoruznjak J, Slade N, Zamola B, Pavelić K, Karminski-Zamola G. Synthesis, photochemical synthesis and antitumor evaluation of novel derivatives of thieno $\left(3^{\prime}, 2^{\prime}: 4,5\right)$ thieno $(2,3-c)$ quinolones. Chem Pharm Bull 2002; 50: 656-60.

17 Hammonds TR, Foster SR, Maxwell A. Increased sensitivity to quinolone antibacterials can be engineered in human topoisomerase II
18 Kamat AM, De Haven JI, Lamm DL. A potential adjunct to intravesical chemotherapy for bladder cancer. Urology 1999; 54: 56-61.

19 Elsea SH, Osheroff N, Nitiss JL. Cytotoxicity of quinolones toward eukaryotic cells. Identification of topoisomerase II as the primary cellular target for the quinolone CP-115, 953 in yeast. J Biol Chem 1992; 267: 13150-3.

20 Nitiss JL. Targeting DNA topoisomerase II in cancer chemotherapy. Nat Rev Cancer 2009; 9: 338-50.

21 Elsea SH, McGuirk PR, Gootz TD, Moynihan M, Osheroff N. Drug features that contribute to the activity of quinolones against mammalian topoisomerase II and cultured cells: correlation between enhancement of enzyme-mediated DNA cleavage in vitro and cytotoxic potential. Antimicrob Agents Chemother 1993; 37: 2179-86.

22 Yogeeswari P, Sriram D, Kavya R, Tiwari S. Synthesis and in-vitro cytotoxicity evaluation of gatifloxacin Mannich bases. Biomed Pharmacother 2005; 59: 501-10.

23 Hammonds TR, Foster SR, Maxwell A. Increased sensitivity to quinolone antibacterials can be engineered in human topoisomerase II alpha by selective mutagenesis. J Mol Biol 2000; 300: 481-91.

24 Sheng Z, Cao X, Peng S, Wang C, Li Q, Wang Y, et al. Ofloxacin induces apoptosis in microencapsulated juvenile rabbit chondrocytes by caspase-8 dependent mitochondrial pathway. Toxicol Appl Pharmacol 2008; 226: 119-27.

25 Smart DJ, Halicka HD, Traganos F, Darzynkiewicz Z, Williams GM. Ciprofloxacin induced G2 arrest and apoptosis in TK6 lymphoblastoid cells is not dependent on DNA double-strand break formation. Cancer Biol Ther 2008; 7: 113-9.

26 Andera L. Signaling activated by the death receptors of the TNFR family. Biomed Pap Med Fac Univ Palacky Olomouc Czech Repub 2009; 153: 173-80.

27 Ott M, Norberg E, Zhivotovsky B. Mitochondrial targeting of tBid/Bax: a role for the TOM complex? Cell Death Differ 2009; 16: 1075-82.

28 Xie CY, Zhu H, Lin LP, Miao ZH, Geng MY, Cai YJ, et al. MFTZ-1, an actinomycetes subspecies derived antitumor macrolide, functions as a novel topoisomerase II poison. Mol Cancer Ther 2007; 6: 3059-70.

29 Chen YC, Lu PH, Pan SL, Teng CM, Kuo SC, Lin TP, et al. Quinolone analogue inhibits tubulin polymerization and induces apoptosis via Cdk1-involved signaling pathways. Biochem Pharmacol 2007; 74: 10-9.

30 Hsu SC, Yang JS, Kuo CL, Lo C, Lin JP, Hsia TC, et al. Novel quinolone CHM-1 induces apoptosis and inhibits metastasis in a human osterogenic sarcoma cell line. J Orthop Res 2009; 27: 1637-44.

31 Patil JB, Kim J, Jayaprakasha GK. Berberine induces apoptosis in breast cancer cells (MCF-7) through mitochondrial-dependent pathway. Eur J Pharmacol 2010; 645: 70-8.

32 Chang YH, Yang JS, Kuo SC, Chung JG. Induction of mitotic arrest and apoptosis by a novel synthetic quinolone analogue, CWC-8, via intrinsic and extrinsic apoptotic pathways in human osteogenic sarcoma U-2 OS cells. Anticancer Res 2009; 29: 3139-48.

33 Herold C, Ocker M, Ganslmayer M, Gerauer H, Hahn EG, Schuppan D. Ciprofloxacin induces apoptosis and inhibits proliferation of human colorectal carcinoma cells. Br J Cancer 2002; 86: 443-8.

34 Wang SW, Pan SL, Huang YC, Guh JH, Chiang PC, Huang DY, et al. CHM-1, a novel synthetic quinolone with potent and selective antimitotic antitumor activity against human hepatocellular carcinoma in vitro and in vivo. Mol Cancer Ther 2008; 7: 350-60. 